\title{
Recuperação de proteínas do soro de leite por meio de coacervação com polissacarídeo
}

\author{
Caroline Dário Capitani(1), Maria Teresa Bertoldo Pacheco(2), Homero Ferracini Gumerato(2), Alfredo Vitali(2) \\ e Flávio Luis Schmidt(2)
}

\begin{abstract}
(1)Universidade Estadual de Campinas, Fac. de Engenharia de Alimentos, Caixa Postal 6121, CEP 13083-970 Campinas, SP. E-mail: carol capitani@yahoo.com.br (2)Instituto de Tecnologia de Alimentos, Av. Brasil, no 2880, Caixa Postal 139, CEP 13073-001 Campinas, SP. E-mail: mtb@ital.sp.gov.br, gumerato@ital.sp.gov.br, avitali@ital.sp.gov.br, schmidt@ital.sp.gov.br
\end{abstract}

\begin{abstract}
Resumo - O objetivo deste trabalho foi recuperar e fracionar as proteínas do soro de leite por meio da técnica de coacervação, utilizando o polissacarídeo carboximetilcelulose sódica (CMC). O soro de leite foi obtido da fabricação industrial do queijo tipo frescal. Foram estudados concentrações do polímero (0,1\% a 0,9\% CMC p/v) e valores de $\mathrm{pH}$, a fim de se obter uma precipitação seletiva das proteínas do soro de leite, sendo as condições otimizadas para produção em piloto. Mediante ajuste gradual, foi possível obter, no $\mathrm{pH} 3$, uma precipitação das proteínas totais (PT/CMC); no $\mathrm{pH} 4$, da $\beta$-lactoglobulina ( $\beta$-Lg/CMC) e, no $\mathrm{pH} 3,2$, a maior proporção de $\alpha$-lactoalbumina $(\alpha-\mathrm{La} / \mathrm{CMC})$. Os coacervados foram separados, por aplicação de força centrífuga, e caracterizados em relação à composição centesimal e perfil eletroforético. $\mathrm{O}$ maior rendimento foi verificado no fracionamento da $\beta$-lactoglobulina, com $86 \%$ de recuperação dessa classe de proteínas do soro desnatado. O coacervado $\beta$-lactoglobulina-CMC ( $\beta$-Lg/CMC) apresenta maior conteúdo protéico, provavelmente em conseqüência da proporção estabelecida entre os hidrocolóides coacervados. O coacervado composto pela $\alpha$-La/CMC apresentou menor conteúdo protéico e porcentagem de recuperação dessas proteínas presentes no soro.
\end{abstract}

Termos para indexação: carboximetilcelulose, $\beta$-lactoglobulina, $\alpha$-lactoglobulina, hidrocolóides coacervados.

\section{Milk whey protein recuperation by coacervation with polysaccharide}

\begin{abstract}
This work aimed to recover and fractionate milk whey proteins through the coacervation technique, using sodium carboxymethyl cellulose (CMC) polysaccharide. Milk whey was obtained from the manufactured cheese type "frescal". Polymer concentration $(0.1-0.9 \% \mathrm{CMC} \mathrm{w} / \mathrm{v})$ and $\mathrm{pH}$ values were studied in order to obtain a selective precipitation of whey proteins; conditions were optimized to pilot scale production. After $\mathrm{pH}$ gradual adjustment the precipitation of total proteins (PT/CMC) was achieved for $\mathrm{pH} 3$; for $\mathrm{pH} 4 \beta$-lactoglobulin ( $\beta$-Lg/CMC) precipitation and for $\mathrm{pH} 3.2$ the greatest proportion of $\alpha$-lactoalbumin $(\alpha-\mathrm{La} / \mathrm{CMC})$ precipitation. Coacervates were separated by centrifuge force, and characterized in relation to their composition and electrophoretic profile. The highest yield was obtained from fractionation of $\beta$ - $\mathrm{Lg} / \mathrm{CMC}$ with precipitation of $86 \%$ of this whey protein type. Highest protein content was showed by $\beta$-Lg/CMC, probably due to the proportion among hydrocolloids. The $\alpha$-La/CMC showed minor protein content and yield recuperation of this whey protein fraction.
\end{abstract}

Index terms: carboxymethyl cellulose, $\beta$-lactoglobulin, $\alpha$-lactoalbumin, hydrocolloids.

\section{Introdução}

O soro do leite é um subproduto resultante da fabricação de queijos, por coagulação da caseína, obtido por adição de ácido ou de enzima (soro doce). Possui alto valor nutricional, conferido pela presença de proteínas com elevado teor de aminoácidos essenciais, destacando-se no conteúdo em sulfurados. Os aminoácidos presentes nas proteínas do soro superam as doses recomendadas a crianças de dois a cinco anos e aos adultos (Wit, 1998; Neves, 2001).
Além das propriedades nutricionais, as proteínas do soro do leite são muito conhecidas pela versatilidade de suas propriedades funcionais tecnológicas como ingredientes em produtos alimentícios, principalmente por sua elevada solubilidade e capacidade de gelificação. Recentemente, têm sido atribuídas às proteínas do soro propriedades funcionais fisiológicas, capazes de produzir um importante controle na modulação do metabolismo e nos mecanismos de defesa dos organismos animal e humano (Sgarbieri \& Pacheco, 1999; Micke et al., 2002; Rosaneli et al., 2002). 
Em relação aos aspectos nutricionais e fisiológicos, as proteínas do soro do leite podem ser usadas em aplicações nutricionais, como fórmulas enterais e infantis; na forma de proteínas nativas ou pré-digeridas contribui com o ganho de peso em pacientes pós-cirúrgicos, geriátricos e imobilizados; numa dieta de alimentos de baixa caloria; e na substituição de gordura, ou na formulação de alimentos e bebidas saudáveis (Lee, 1996; Wit, 1998).

No Brasil, a produção de bebidas lácteas é uma das principais opções de aproveitamento do soro do leite, e as mais comercializadas são as bebidas fermentadas, com características sensoriais semelhantes ao iogurte, e bebidas lácteas não-fermentadas. Contudo, o aproveitamento desse subproduto atinge apenas $15 \%$ do total de soro produzido, com a produção nacional, em 2002, estimada em 470 milhares de toneladas (Neves, 2001; Nakamae, 2004).

O desenvolvimento de técnicas de fracionamento, de modificação e de preservação das proteínas do soro pode contribuir para a recuperação desse valioso nutriente, assim como melhorar a expressão de suas propriedades funcionais. Embora a técnica de fracionamento seletivo das proteínas do soro tenha sido explorada em laboratório (Hidalgo \& Hansen, 1971), não foi realizado nenhum estudo para otimização do processo e sua viabilização em escala piloto, pelo processo de coacervação. O desenvolvimento desta tecnologia em maior escala pode servir como oportunidade de negócio para o setor lactinicista, podendo contribuir com a diversificação de produtos e agregação de valor ao resíduo da produção de queijo.

O objetivo deste trabalho foi estabelecer parâmetros de $\mathrm{pH}$ e concentração de polissacarídeo para recuperação das proteínas do soro de leite, comparar e caracterizar as frações obtidas e verificar o rendimento e a viabilidade técnica do processo em escala piloto.

\section{Material e Métodos}

O soro de leite foi proveniente da fabricação industrial do queijo tipo frescal, de um laticínio de pequeno porte, situado no Município de Espírito Santo do Pinhal, SP. Em virtude do elevado teor de lipídeos no soro (1\% base úmida), foi realizada a desnatação antes do processo de coacervação. Na desnatação, o soro foi aquecido a $40^{\circ} \mathrm{C}$ e centrifugado em uma centrífuga de pratos, com velocidade máxima de $8.000 \mathrm{rpm}$.

O hidrocolóide utilizado foi a carboximetilcelulose sódica, com grau de substituição de 0,65 a 0,85 . A solubilização da goma foi realizada em homogeneizador de hélice, à velocidade de $2.000 \mathrm{rpm}$. O polissacarídeo foi disperso lentamente em água destilada, à temperatura de $22 \pm 1^{\circ} \mathrm{C}$, sob agitação, até completa solubilização do material. A dispersão foi preparada de véspera e deixada em repouso sob refrigeração, de modo a garantir a hidratação completa do hidrocolóide.

A reação de interação das proteínas do soro com a carboximetilcelulose foi realizada inicialmente por testes em laboratório à temperatura ambiente $\left(25^{\circ} \mathrm{C}\right)$, com diferentes concentrações de CMC (0,1\%, 0,3\%, 0,6\% e $0,9 \%$ p/v). A eficiência do processo foi monitorada pelo teor de proteínas nos sobrenadantes e precipitados. Definida a melhor concentração da solução de CMC, na precipitação das proteínas, variou-se o $\mathrm{pH}$ na faixa de 2,5 a 4,5, para verificação da influência desse parâmetro na obtenção da máxima precipitação protéica.

Os fluxogramas dos processos de obtenção dos coacervados encontram-se nas Figuras 1 e 2. Como descrito no fluxograma da Figura 1, definiu-se trabalhar com o pH 4 para recuperação da $\beta$-Lg e, 3,2 para $\alpha$-La, a partir dos resultados obtidos em laboratório, utilizando-se como referência ao trabalho de Hidalgo \& Hansen (1971). Quanto à fração PT/CMC, o pH foi ajustado para 3,0.

Adicionalmente foram avaliados, em escala piloto, a velocidade do fluxo de alimentação da matéria-prima à centrífuga, a velocidade de centrifugação e o rendimento dos coacervados. Utilizou-se um volume de $50 \mathrm{~L}$ de soro de leite desnatado, ao qual se adicionou volume equivalente da dispersão de CMC $(0,3 \% \mathrm{p} / \mathrm{v})$. O soro e a solução de $\mathrm{CMC}(0,3 \% \mathrm{p} / \mathrm{v})$, à temperatura de $22 \pm 1^{\circ} \mathrm{C}$, tiveram os valores de $\mathrm{pH}$ ajustados com $\mathrm{HCl} 1 \mathrm{~N}$, para os valores desejados (4; 3,2 e 3), de acordo com o precipitado a ser obtido. Depois de ser efetuada a mistura nas devidas proporções (Figuras 1 e 2), lotes com 100 L contendo os complexos foram conduzidos em fluxo de alimentação contínua para a centrifugação, em centrífuga de cesto GEDR-Heinel (modelo 2250, no de série 48586). No controle e otimização do fluxo de alimentação da matéria-prima, na centrífuga de cesto, utilizou-se bomba peristáltica de fluxo contínuo.

De modo a elevar o rendimento de recuperação da fração $\alpha$-lactoalbumina, foi realizado aquecimento a $80^{\circ} \mathrm{C}$ por 5 min no sobrenadante 2 , que continha a $\alpha$-La solúvel. Todo material para análise foi desidratado pelo processo de liofilização.

O soro de leite e os coacervados foram caracterizados quanto à composição centesimal, por meio dos métodos descritos pela AOAC (1990). Na determinação da 
proteína bruta, o nitrogênio total foi multiplicado pelo fator 6,38. A lactose foi determinada pelo método de Acton (1977).

A fim de identificar os tipos de proteínas predominantes nos coacervados, foi realizada a técnica de eletroforese em gel SDS-Page, em que as proteínas são separadas por faixa de peso molecular. Para isso, utilizouse o equipamento Phast-system, e padrões de baixo peso molecular (Sigma M3913) e de $\beta$-lactoglobulina (Sigma L4756). As amostras foram dissolvidas em tampão Tris-HCl 10 mM a pH 8.0, em uma concentração final de aproximadamente $0,5 \mathrm{mg} \mathrm{mL}^{-1}$ (Laemmli, 1970).

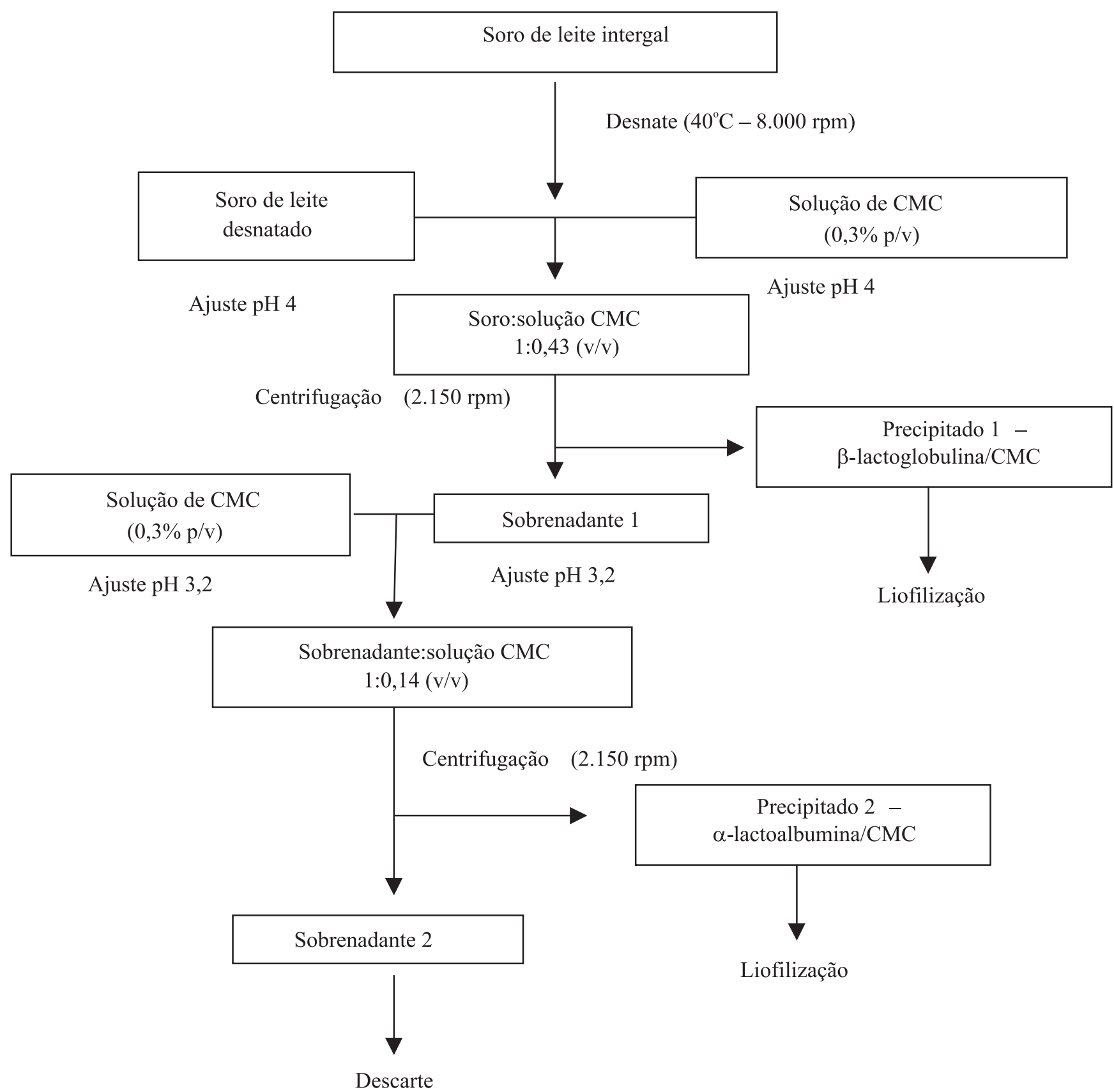

Figura 1. Fluxograma de obtenção das principais frações protéicas do soro, $\beta$-lactoglobulina e $\alpha$-lactoalbunina, complexadas com carboximetilcelulose (CMC). 


\section{Resultados e Discussão}

Os melhores resultados de formação dos complexos coacervados foram alcançados com a concentração de $0,3 \%$ (p/v) de CMC (Figura 3), que resultou em menores valores de proteínas residuais, depois da separação dos coacervados por centrifugação. Esses valores foram de $6,01 \%$ no sobrenadante, utilizando-se a concentração de CMC a $0,3 \%$, e de apenas $4,7 \%$ no sobrenadante 2 , teores que indicam elevada precipitação das proteínas coacervadas com CMC, nessa concentração.

Os resultados (Figura 3) concordam com o descrito na literatura, segundo a qual a coacervação das proteínas do soro com polissacarídeos aniônicos resulta em melhor recuperação protéica, na concentração ao redor de 0,25\% de CMC (p/v) (Mann \& Malick, 1996).

A maior parte das interações que ocorrem no processo de coacervação complexa é do tipo eletrostática, por isso é necessário que os valores de $\mathrm{pH}$ do meio de reação estejam abaixo do ponto isoelétrico (pI) das proteínas

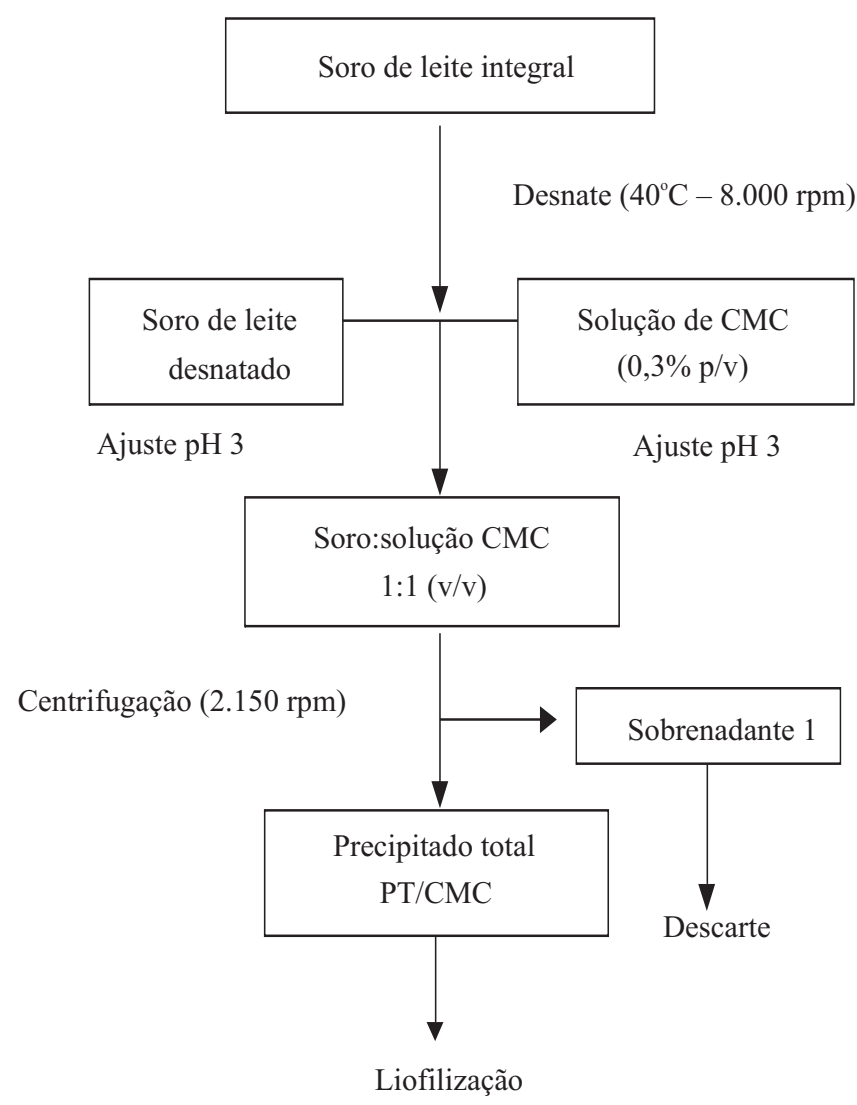

Figura 2. Fluxograma de obtenção de proteínas totais (PT) do soro complexadas com carboximetilcelulose (CMC). do soro, onde se apresentam suficientemente protonadas, para que ocorra a reação de complexação com polissacarídeos aniônicos. Sabe-se que o pI da $\beta$-lactoglobulina ( $\beta$-Lg) encontra-se na faixa de 5,2 , e da $\alpha$-lactoalbumina ( $\alpha$-La) entre 4,2 e 4,5 (Schmitt et al., 1998).

No pH 3 houve diferença significativa entre as médias de concentração de proteínas nos sobrenadantes ( $>>0,05)$, portanto, optou-se por este valor de $\mathrm{pH}$ para precipitar a fração PT/CMC (Figura 4). Na faixa de pH 3 (Figura 5), onde ocorreu máxima precipitação de proteínas, provavelmente houve maior balanço entre as

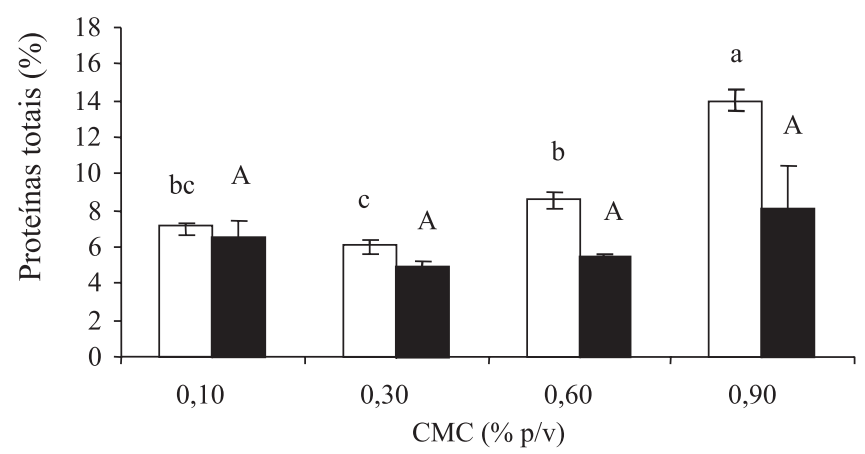

Figura 3. Concentração de proteínas totais nos sobrenadantes 1 () e 2 ( $\square$ ), após a complexação e precipitação das frações, com diferentes concentrações de carboximetilcelulose (CMC). Letras iguais, minúsculas do sobrenadante 1 e maiúsculas do sobrenadante 2, indicam que não existe diferença significativa entre as concentrações $(p<0,05)$ pelo teste de Tukey.

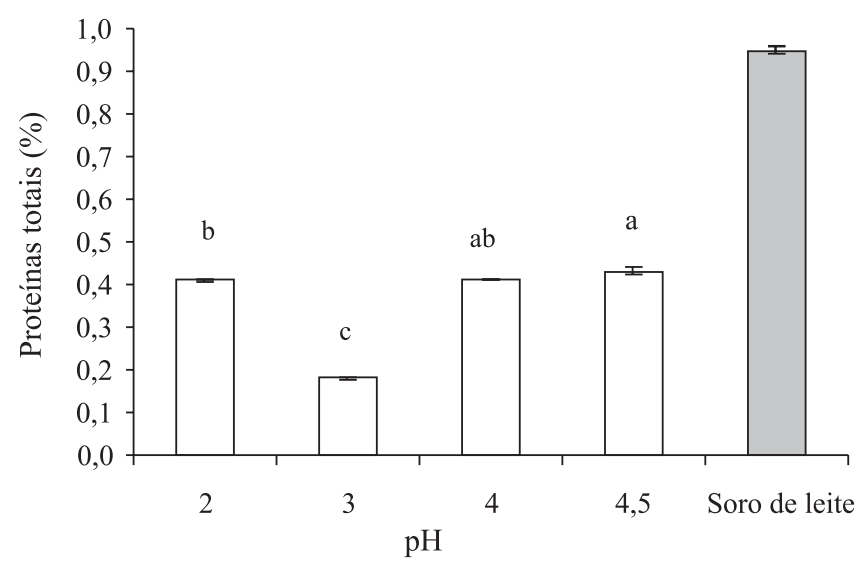

Figura 4. Concentração de proteínas totais no sobrenadante depois de precipitação com carboximetilcelulose a 0,3\% (p/v) na relação 3:1 (proteínas:polissacarídeos p/p) em diferentes $\mathrm{pH}$, e no soro de leite desnatado. Letras iguais indicam que não existe diferença significativa entre os valores de $\mathrm{pH}$ $(\mathrm{p}<0,05)$ pelo teste de Tukey. 
cargas negativas no carboidrato e cargas positivas nas proteínas. Nesse $\mathrm{pH}$, os sítios de ligação das proteínas, carregados positivamente, são grupos amino, que realizam ligação com os grupos carboxílicos protonados da goma (Tolstoguzov, 1997, 1998; Fonseca \& Bradley Junior, 2001).

Os perfis eletroforéticos dos complexos $\beta$-Lg/CMC, $\alpha$-La/CMC e PT/CMC, obtidos por coacervação em pH ácido estão apresentados na Figura 5. As proteínas foram precipitadas de maneira seletiva, ou seja, apesar de haver frações protéicas contaminantes, foi possível a obtenção de amostras ricas em $\beta$-Lg e em $\alpha$-La, classificadas como $\beta$-Lg/CMC e $\alpha$-La/CMC, respectivamente. Como se esperava, a amostra de PT/CMC contém, além das duas frações protéicas principais, a albumina de soro bovina (BSA) e a imunoglobulinas (Figura 5).

No trabalho de Hidalgo \& Hansen (1971), citado como referência no método de obtenção dos coacervados, foi observado, por meio de eletroforeses, que em $\mathrm{pH} 4$, a $\beta$-Lg se apresenta coacervada e, no sobrenadante residual da precipitação, há presença predominante da fração $\alpha$-La, o que indica que, nesse $\mathrm{pH}$, essa proteína não se precipita. Porém, em pH 3,2, utilizando-se uma solução de CMC 0,37\%, a fração $\alpha$-La apresentou maior proporção no coacervado complexo.

Os resultados da caracterização das amostras de soro de leite e dos coacervados (liofilizados) quanto à composição química parcial encontram-se descritos na Tabela 1. A concentração inicial de proteínas, no soro de leite integral, foi de aproximadamente $12 \%$ (em base seca). Devido ao elevado teor de lipídeos nessa amos-

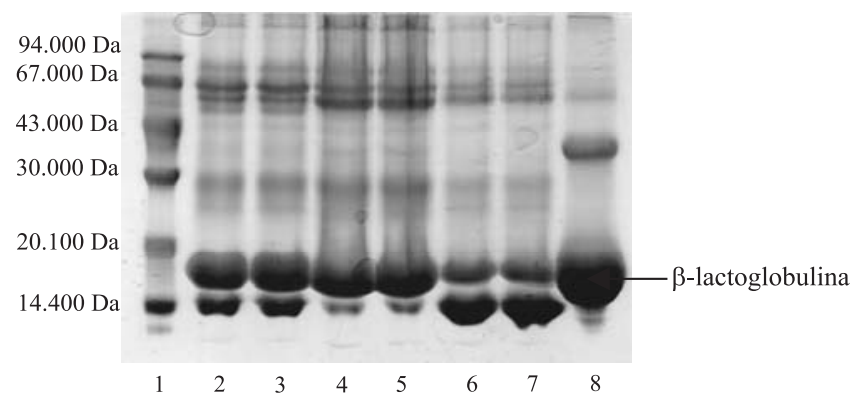

Figura 5. Eletroforese SDS-Page, em gel 12,5\% de poliacrilamida, mostrando na coluna 1 , um padrão de baixo peso molecular; nas colunas 2 e 3, fração de proteína total/ CMC; nas colunas 4 e 5, fração de $\beta$-lactoglobulina/CMC; nas colunas 6 e 7 , fração $\alpha$-lactoalbumina/CMC; e na coluna 8 , um padrão de $\beta$-lactoglobulina. tra, foi realizada a desnatação do soro antes da complexação, o que acabou elevando o teor de proteínas e de outros componentes.

A fração $\beta$-Lg/CMC arrastou maior quantidade de lipídeos, com aumento de cerca de dez vezes sua concentração em relação ao soro de leite desnatado. Comportamento similar foi observado para o complexo PT/CMC.

Observou-se que a fração $\beta$-Lg/CMC contém maior teor de proteínas do que as demais, tendo comprovado maior rendimento na etapa de complexação e de fracionamento (Tabela 2). O rendimento máximo alcançado para o precipitado 1 (coacervado de $\beta$-Lg/CMC), em relação à porcentagem de proteínas recuperada do soro, foi confirmado pela menor quantidade da proteína $\beta$-lactoglobulina no sobrenadante, depois da primeira precipitação (pH 4; 0,3\% CMC). Esse resultado pode ser justificado pelo fato de a $\beta$-lactoglobulina ser a fração protéica mais abundante no soro, e por apresentar quase $50 \%$ de sua estrutura na forma desorganizada, tornando-a sensível e reativa às variações de $\mathrm{pH}$ e a outras alterações do meio (Modler, 2000; Pacheco et al., 2002).

O melhor rendimento de coacervação é alcançado quando há uma proporção ideal de mistura das moléculas por peso, que, por meio da manipulação dos valores de $\mathrm{pH}$, poderá proporcionar uma razão equivalente de cargas opostas entre os polímeros ionizados. Esse valor de pH é chamado de pH de equivalência (Schmitt et al., 1998).

Tabela 1. Composição centesimal do soro de leite desnatado e das amostras de proteínas complexadas com carboximetilcelulose (CMC), em base seca(1).

\begin{tabular}{lrrrr}
\hline Determinações & Soro de leite & \multicolumn{3}{c}{ Amostras de proteínas } \\
\cline { 3 - 5 } & desnatado & $\beta$-Lg/CMC & $\alpha$-La/CMC & \multicolumn{1}{c}{ PT/CMC } \\
\hline Proteínas totais (\%) & $13,05 \pm 0,43$ & $57,23 \pm 0,32$ & $35,96 \pm 1,73$ & $48,33 \pm 0,53$ \\
Lipídeos totais (\%) & $0,89 \pm 0,05$ & $9,42 \pm 0,01$ & $3,21 \pm 0,002$ & $7,37 \pm 0,13$ \\
Resíduo mineral (\%) & $9,31 \pm 0,05$ & $1,98 \pm 0,96$ & $4,14 \pm 1,81$ & $1,76 \pm 0,04$ \\
Lactose (\%) & $76,73 \pm 0,32$ & $31,37 \pm 0,29$ & $56,69 \pm 0,47$ & $42,54 \pm 0,22$ \\
\hline
\end{tabular}

${ }^{(1)} \beta$-Lg: $\beta$-lactoglobulina; $\alpha$-La: $\alpha$-lactoalbunina; PT: proteína total.

Tabela 2. Rendimento e recuperação protéica, nas amostras de proteínas complexadas com carboximetilcelulose (CMC), por liofilização a partir de 100 L de soro de leite desnatado.

\begin{tabular}{lcc}
\hline Amostra & Peso $(\mathrm{g})$ & Rendimento $(\%)$ \\
\hline Proteína total CMC & 800 & 53 \\
$\beta$-lactoglobulina/CMC & 600 & 86 \\
$\alpha$-lactoalbunina/CMC & 100 & 31 \\
\hline
\end{tabular}


A amostra $\alpha$-La/CMC, embora tenha resultado em menor teor de lipídeos e proteínas, apresenta maior conteúdo de carboidratos proveniente da readição de CMC, na proporção de 1:1,5 (proteína:CMC), nessa etapa do processamento. Parte dessa proteína permaneceu solúvel depois da precipitação dessa fração, como pode ser observado na Figura 5. O aquecimento do sobrenadante 2 (com teores elevados de $\alpha$-La) não resultou em acréscimo de rendimento dessa fração precipitada na forma de coacervado. Contudo, observou-se que a presença de $\mathrm{NaCl}$, remanescente do processo de fabricação do queijo, em algumas amostras de leite, pode ser favorável à recuperação dessa fração (Modler, 2000).

Com relação ao fluxo de alimentação da matéria-prima, os valores otimizados foram de vazão de $21 \mathrm{~L} \mathrm{~h}^{-1}$ para a obtenção do primeiro precipitado ( $\beta$-Lg/CMC) e de $11 \mathrm{~L} \mathrm{~h}^{-1}$ para o segundo ( $\alpha$-La/CMC). A velocidade de centrifugação de 2.150 rpm mostrou-se mais eficiente para a separação das frações precipitadas. Depois da otimização do processamento em escala piloto, foi possível observar o rendimento de cada fração complexada e centrifugada. O rendimento das amostras secas, obtidas por meio do processamento de aproximadamente $100 \mathrm{~L}$ de soro de leite desnatado, foi de cerca de $600 \mathrm{~g}$ de $\beta$-Lg/CMC; $100 \mathrm{~g}$ de $\alpha$-La /CMC e 800 g de PT/CMC (Tabela 2).

Ao analisar a matéria seca total, obtida a partir de $100 \mathrm{~L}$ de solução, observou-se que a maior quantidade de complexo seco foi alcançada com a fração PT/CMC (Tabela 2), em que o complexo arrastou quantidades equivalentes de proteína e CMC em conseqüência da relação estequiométrica de 1:0,33 (p/p) de proteínas e CMC.

\section{Conclusões}

1. Mediante as condições de pH e concentração de CMC utilizadas, é possível obter complexos coacervados ricos em $\beta$-Lg, $\alpha$-La e um terceiro composto das principais frações protéicas do soro lácteo (PT/CMC).

2. A fração $\beta$-lactoglobulina ( $\beta$-Lg/CMC) apresenta o maior rendimento (86\%) de recuperação por classe de proteína, sendo o maior rendimento em massa para as proteínas totais/CMC (PT/CMC).

\section{Referências}

ACTON, G.H. The determination of lactose in cheese. Australian Journal of Dairy Technology, v.9, p.111-114, 1977.
AOAC. Official methods of analysis. $15^{\text {th }}$ ed. Washington: Horwitz W, 1990. 1018p.

FONSECA, L.M.; BRADLEY JUNIOR, R. Precipitação de proteínas por meio de coacervação com carboidratos complexos. Revista do Instituto “Cândido Tostes”, v.56, p.341-348, 2001.

HIDALGO, J.; HANSEN, M.T. Selective precipitation of whey proteins with carboxymethylcellulose. Journal of Dairy Science, v.54, p.1270-1274, 1971.

LAEMMLI, V.K. Cleavage of structural proteins during the assembly of the head of bacteriophage $T_{4}$. Nature, v.227, p.680-685, 1970.

LEE, M.H. Processing whey protein for use as a food ingredient. Food Technology, v.50, p.49-52, 1996.

MANN, B.; MALIK, R.C. Studies on some functional characteristics of whey protein-polysaccharide complex. Journal of Food Science and Technology, v.33, p.202-206, 1996.

MICKE, P.; BEEH, K.M.; BUHL, R. Effects of long-term supplementation with whey proteins on plasma glutathione levels of HIV-infected patients. European Journal of Nutrition, v.41, p.12-18, 2002.

MODLER, H.W. Milk processing. In: NAKAI, S.; MODLER, H.W. (Ed.). Food proteins: processing applications. Canada: Wiley-VCH, 2000. p.1-88.

NAKAMAE, I.J. (Ed.). Anualpec 2004: anuário da pecuária brasileira. São Paulo: FNP, 2004. p.191-232.

NEVES, B.S. Aproveitamento de subprodutos da indústria de laticínios. In: EMBRAPA GADO DE LEITE. Sustentabilidade da pecuária de leite no Brasil: qualidade e segurança alimentar. Juiz de Fora, MG, 2001. p.97-108.

PACHECO, M.T.B.; AMAYA-FARFAN, J.; SGARBIERI, V.C. Partial characterization of a whey protein concentrate and its enzyme hydrolysates. Journal of Food Biochemistry, v.26, p.327-338, 2002. ROSANELI, C.F.; BIGHETTI, A.E.; ANTÔNIO, M.A.; CARVALHO, J.E.; SGARBIERI, V.C. Efficacy of a whey protein concentrate on the inhibition of stomach ulcerative lesions caused by ethanol ingestion. Journal of Medicinal Food, v.5, p.221-228, 2002.

SCHMITT, C.; SANCHEZ, C.; DESODOBRY-BANON, S.; HARDY, J. Structure and technofunctional properties of proteinpolysaccharide complexes: a review. Critical Reviews in Food Science and Nutrition, v.38, p.689-753, 1998.

SGARBIERI, V.C.; PACHECO, M.T.B. Alimentos funcionais fisiológicos. Brazilian Journal of Food Technology, v.2, p.7-19, 1999.

TOLSTOGUZOV, V.B. Functional properties of proteinpolysaccharide mixtures. In: HILL, S.E.; LEDWARD, D.A.; MITCHELL, J.R. Functional properties of food macromolecules. Gaithersburg, Maryland: Aspen, 1998. p.252-277.

TOLSTOGUZOV, V.B. Protein polysaccharide interactions. In: DAMODARAN, S. Food proteins and their applications. New York: M. Dekker, 1997. p.171-198.

WIT, J.N. de. Nutritional and functional characteristics of whey proteins in food products. Journal of Dairy Science, v.81, p.597-608, 1998.

Recebido em 23 de junho de 2004 e aprovado em 16 de abril de 2005 